To be submitted to Materials Science and Engineering A, June 2016

\title{
Effect of Indentation Temperature on Nickel-Titanium Indentation-Induced Two-Way Shape-Memory Surfaces
}

Stephan A. Brinckmann ${ }^{1}$, Mareike Frensemeier ${ }^{2}$, Christopher M. Laursen ${ }^{1}$, Hans J. Maier ${ }^{3}$, Dominik Britz ${ }^{4}$, Andreas S. Schneider ${ }^{5}$, Frank Mücklich ${ }^{4}$, and Carl P. Frick ${ }^{1, \Omega}$

1. University of Wyoming, Mechanical Engineering Department, Laramie, USA

2. INM - Leibniz Institute for New Materials, Saarbrücken, Germany

3. Leibniz University of Hannover, Institute for Materials Science, Garbsen, Germany

4. Saarland University, Department of Materials Science and Engineering, Saarbrücken, Germany

5. AG der Dillinger Hüttenwerke, Development and Plate-Design, Dillingen

$\Omega$ Corresponding author: Tel.: 13077664068

E-mail address: cfrick@uwyo.edu (C.P.Frick)

Keywords: NiTi; Shape Memory Alloy; Two-way Shape Memory Effect; Vickers Indentation; Microstructure; Martensite

\begin{abstract}
:
This study investigated the effect of temperature on indentation-induced one-way and twoway shape memory properties in Ti-50.3 at.\%Ni alloy. Indentation temperatures ranged from below the martensite finish temperature $\left(M_{f}\right)$ to above the austenite finish temperature $\left(A_{f}\right)$ with the explicit intent of varying the indented phase. Samples used in the study were characterized by differential scanning calorimetry and transmission electron microscopy (TEM). The topographical behavior of the shape memory effect was investigated through Vickers indentation and laser scanning 3D confocal measurements. The magnitudes of deformation recovery associated with the one-way and two-way shape-memory effect (OWSME, TWSME) decreased with increasing indentation temperatures, which is a reflection of the decreasing volume of material experiencing martensitic reorientation during indentation. Indented and subsequently planarized samples exhibited TWSME protrusions when thermally cycled. Laser scanning measurements were used to characterize the height of the protrusions as increasing depths of material were polished away, which provided insight into the overall affected volume beneath the indent. As indentation temperatures increased, both the height of the protrusions, and consequently the polish depth necessary to completely remove the effect, decreased. TEM investigations revealed that directly underneath a nanoindent the microstructure was very fine due to the high-strain deformation; this was contrasted with a much coarser grain size in the undeformed bulk material. Overall these results strongly imply that the deformation recovery associated with the OWSME and TWSME can be maximized by indenting at temperatures at $M_{f}$ or below because the volume of deformed microstructure beneath the indent is maximized. This finding has important practical value for any potential application that utilizes indentation-induced phase transformation deformation recovery in NiTi.
\end{abstract}




\section{Introduction:}

Near-equiatomic nickel titanium (NiTi) alloys exhibit shape memory properties that can recover apparent permanent deformations upon heating (shape memory) or spontaneously during unloading (pseudoelasticity) (Otsuka \& Wayman 1998; Otsuka \& Ren 2005; Miyazaki et al. 1982; Tas et al. 1972; Benafan et al. 2012). The shape memory deformation recovery is owed to a reversible phase transformation from a B19' martensitic crystal structure to a B2 austenitic structure upon heating (Otsuka \& Ren 2005). This one-way shape memory effect (OWSME) has been observed for any loading condition including tension ( $\mathrm{Ng} \&$ Sun 2006; Shaw 1995; Erbstoeszer et al. 2000; Wasilewski 1975; Buehler et al. 1963), compression (Vaidyanathan et al. 1999; Laplanche et al. 2014a; Laplanche et al. 2014b; Wasilewski 1975; Buehler et al. 1963), and indentation (Shaw et al. 2003; Ni et al. 2002; Zhang et al. 2005; Huang et al. 2005; Frick et al. 2005). The phase transformation behavior is extremely dependent on alloy composition and deformation processing history. Increasing the relative nickel content decreases the phase transformation temperatures by approximately $220{ }^{\circ} \mathrm{C} / \mathrm{at} . \% \mathrm{Ni}$ (Tang 1997), which will have a profound effect on stress-strain behavior. Plastic deformation associated with deformation processing has a similar effect, impeding the stress-induced phase transformation, although the microstructural effects are more complex (Liu \& Favier 2000; Lin \& Wu 1993; Mahmud et al. 2008; Li et al. 2008).

NiTi also exhibits a two-way shape memory effect (TWSME) (Wasilewski 1975; Perkins 1974; Nagasawa et al. 1974). This TWSME is the material's ability to "remember" both a hot and a cold state and subsequently transition between these two states based on a phase transition from martensite to austenite and vice-versa. It has been noted that the methods of eliciting the TWSME can be categorized into three general methods: thermo-mechanical training (Lahoz et al. 2002; Lahoz \& Puértolas 2004; Scherngell \& Kneissl 1999; Scherngell \& Kneissl 2002; Liu \& McCormick 1990), severe deformation below the martensite start temperature $\left(M_{s}\right)$ (Benafan et al. 2012; Perkins 1974; Nagasawa et al. 1974; Liu et al. 1998; Lahoz et al. 2002; Eggeler et al. 2004), and stress-assisted aging (Fukuda et al. 2001; Sato et al. 1998; Fukuda et al. 1997; Nishida \& Honma 1984). More recently it has been shown that the TWSME can be induced in NiTi through an indentation method (Ni et al. 2002; Zhang et al. 2006; Su et al. 2007). Not only has the indentation-induced shape memory effect been observed in materials below the martensite finish temperature $\left(M_{f}\right)$, it has also been observed for indentation of austenitic NiTi (Qin et al. 2014; Frensemeier et al. 2015). Additionally, it has been shown that subsequently planarizing these indents followed by thermal cycling leads to reversible TWSME surface protrusions that are reversible over several cycles (Qin et al. 2014; Frensemeier et al. 2015; Peter et al. 2013; Zhang, Cheng \& Grummon 2007; Fei et al. 2009). Although a handful investigations have proposed theories on the underlying mechanisms leading to this indentation induced TWSME ( $\mathrm{Su}$ et al. 2007; Zhang, Cheng \& Grummon 2007; Fei et al. 2009), the complex mechanisms on the microstructural scale remain to be experimentally uncovered and a comprehensive understanding has not yet been widely agreed upon.

In a recent publication, Qin et al. investigated the indentation-induced OWSME and TWSME in a NiTi alloy which is in the austenite phase at room temperature. Transmission electron microscopy (TEM) uncovered that both dislocations and thermally stable martensitic plates are present and parallel to the indenter geometry at temperatures in which the material is expected to be fully austenitic (Qin et al. 2014). Complementary to those results, a separate study has shown that indentation-induced TWSME diminishes and disappears with heating to temperatures well 
above the austenite finish temperature $\left(A_{f}\right)$, indicating that the thermally stable martensite underneath the indent reverts to austenite above $A_{f}$ (Frensemeier et al. 2015). Combined, these studies strongly suggest that residual, stress-stabilized martensite plays a dominant role in indentation-induced TWSME.

The stress-level necessary to induce martensite varies linearly with elevating temperatures following the Clausius-Clapeyron relation, thus with an increase in temperature, the stress required to initiate and propagate this transformation also increases (Adler et al. 1990; Tang et al. 1991). However, there is a critical temperature at which this stress-induced martensite is no longer energetically favorable and the deformation mechanism of the NiTi is ultimately shifted to plastic deformation of the austenite (Faiella \& Antonucci 2015). In contrast to uniaxial loading, indentation produces a much more complex stress state and several studies have demonstrated indentation-induced recovery when indented at temperatures above $A_{f}$. It is believed that the large component of hydrostatic stress from indentation (Suresh \& Giannakopoulos 1998; Larsson et al. 1996) assists in shifting the transformation temperatures (Zhang et al. 2005; Patel \& Cohen 1953). As thermally stable martensite has been uncovered in indented austenitic NiTi (Qin et al. 2014), this stress-induced transformation may play a pivotal role in the manifestation of the indentationinduced TWSME.

The goal of this study was to further understand the inherent mechanisms necessary for the TWSME to occur, as a function of the temperature at which the sample is indented. A Ti-50.3 at.\% $\mathrm{Ni}$ alloy was indented at temperatures ranging from $19^{\circ} \mathrm{C}$ below $M_{f}$ to $31^{\circ} \mathrm{C}$ above $A_{f}$, thereby, these temperatures span the martensitic and austenitic states. The recovery ratios of both the OWSME and the TWSME were measured as a function of increasing indentation temperature. Through this, an understanding of the volume of material that affects the TWSME could be reached and related to indentation temperature. In addition to these experiments, indented samples were investigated using transmission electron microscopy (TEM) and the microstructure of the material exhibiting the TWSME was examined.

\section{Experimental:}

The material used in this study was a commercially available NiTi with a composition of Ti-50.3 at.\% Ni (Ti-55.4 wt.\% Ni). As the bulk plate was likely heavily deformed during material processing, the material was solutionized at $1000^{\circ} \mathrm{C}$ for 24 hours and immediately water quenched. The phase transition temperatures of both the solutionized and as-received materials were measured using differential scanning calorimetry (DSC) on a Mettler Toledo DSC1 Star System. Tests were conducted using a heating/cooling rate of $10^{\circ} \mathrm{C} / \mathrm{min}$ starting from room temperature, initially heating to $120^{\circ} \mathrm{C}$ and cycled to a low temperature of $-80^{\circ} \mathrm{C}$ before returning to the start temperature. Masses of the samples analyzed were between $10 \mathrm{mg}$ and $30 \mathrm{mg}$. Three full heating and cooling cycles were performed for both the as-received and solutionized samples. Using the DSC data, the transformation temperatures were calculated using a two-tangent method.

For indentation, samples were prepared perpendicular to the drawing direction and cut from the bulk sample to a working size of $5 \mathrm{~mm} \times 8 \mathrm{~mm}$. Prior to indentation, these samples were cold mounted in epoxy and ground using a progressively lower grit size to 1200 (P-4000) grit SiC paper followed by a $1 \mu \mathrm{m}$ diamond suspension and a $50 \mathrm{~nm}$ colloidal silica polish. Finally, samples were electropolished in an electrolyte solution consisting of $20 \%$ volume $\mathrm{H}_{2} \mathrm{SO}_{4}$ and $80 \%$ volume methanol at room temperature. 
Microindentation was performed on an MTS 858 Mini Bionix ${ }^{\circledR}$ II load frame equipped with a Vickers indenter tip. A maximum load of $50 \mathrm{~N}$ at a loading rate of $1 \mu \mathrm{m} / \mathrm{sec}$ was used for each indent. This load was held constant for 30 seconds prior to unloading at the same rate. Samples were indented at temperatures ranging from $-10^{\circ} \mathrm{C}$ to $120^{\circ} \mathrm{C}$ with the aim to examine the magnitude of the shape memory effects with changing temperature. Indentation at temperatures other than room temperature was achieved using either an MTS 651 environmental chamber (temperatures $-10^{\circ} \mathrm{C}$ to $85^{\circ} \mathrm{C}$ ) or using a heat gun (indentation at $90{ }^{\circ} \mathrm{C}$ and above).

All samples, regardless of indentation temperature, were first fully cooled below $M_{f}$ before being heated to their indentation temperature, such that samples were fully martensitic at indentation temperatures below $A_{s}$. Similarly, between $A_{s}$ and $A_{f}$, samples are expected to have some combination of phases during indentation, and indentation temperatures above $A_{f}$ ensured a fully austenitic phase.

Samples for measuring the recovery ratio were each indented four times spaced $750 \mu \mathrm{m}$ apart. Subsequently, the indentation depths of the samples were measured with an Olympus OLS4000 laser scanning confocal microscope capable of 3D measurements with a depth resolution of $10 \mathrm{~nm}$. To determine the magnitude of both the OWSME and TWSME, indents were measured in three states: initially after indentation, heated above $A_{f}$, and cooled below $M_{f}$. Heating of samples was performed in situ using a ceramic heater underneath the microscope. Comparison of the initial indent with the heated indent yielded the OWSME. The reversible TWSME was observed through measurements of the initial, heated, and cooled indentation depths.

To measure the recovery of the protrusions as a function of polishing depth, samples were initially indented at the corners of the rectangular samples with a $120^{\circ}$ diamond spheroconical indenter to much larger indentation depths of about $120 \mu \mathrm{m}$. These indents were used as reference for the amount of material polished away. Afterwards, the samples were microindented six times in a similar fashion as previously described and post-indentations were thermally cycled to recover the shape change induced by the OWSME. The samples were then planarized and polished until the initial indents were removed, leaving only the deeper reference indentations. Measurement of the subsequent protrusion height upon heating above $A_{f}$ was accomplished using an identical in situ heating method as described for the recovery ratio samples using the confocal microscope. After measuring the protrusion height, samples were cooled below $M_{f}$ and further polished until roughly 3-5 $\mu$ m of material was removed. Then the material was heated above $A_{f}$ and protrusion heights were recorded an additional time. This process continued until no recurring shape change could be measured upon heating.

The microstructure of the material volume close to indents made by instrumented nanoindentation was examined by TEM. For TEM, nanoindenation was performed instead of microindentation so that a deformation gradient beneath the indent can be observed in a single TEM lamella. To decrease to final surface roughness for nanoindentation, the electropolishing step was replaced by a 1 hour vibratory polish using a $0.02 \mu \mathrm{m}$ colloidal silica suspension. Nanoindentation used the same Vickers tip as in micro-indentation; however, an Agilent Technologies G200 Nano-Indenter was used to apply load. Samples were loaded to a target depth of $300 \mathrm{~nm}$ at a displacement rate of $15 \mathrm{~nm} / \mathrm{s}$, and the target depth was held for 30 seconds before unloading. Indents were spaced at least $100 \mu \mathrm{m}$ apart.

From a representative $300 \mathrm{~nm}$ indentation in the solutionized material, a TEM lamella was fabricated using a dual beam Zeiss Auriga focused ion beam (FIB). A JEOL JEM-2010 TEM was 
used to capture TEM bright-field images along with corresponding selected area electron diffraction (SAED) patterns investigate the microstructure both below the indent itself and at a depth of $5 \mu \mathrm{m}$ underneath the indented material. TEM was also used to characterize the initial microstructure of the as-received material. To investigate the difference in microstructure of the solutionized sample, a polished sample was chemically etched and imaged with an Olympus BH2 optical microscope. Grain size was subsequently measured using the line-intersect method.

\section{Results:}

DSC Analysis:

The average phase transition temperatures of the three cycles of both samples examined as found by DSC are tabulated within one standard deviation in Table 1 and plotted in Figure 1. The solutionized sample displays a single step endothermic austenite to martensite transformation upon cooling, and the reverse exothermic transformation upon heating. Such a curve is typical for Ti50.3at.\%Ni, indicating a direct and reversible austenite/martensite transformation (Liu et al. 2008; Liu et al. 2006). The as-received sample differs significantly from this behavior and upon cooling a two-step transition from austenite to martensite is seen. This two-step behavior is associated with an intermediate phase commonly referred to as the "R-phase" (Sehitoglu et al. 2001; Lin et al. 1991; Ling \& Kaplow 1980; Miyazaki \& Otsuka 1986) and the transition temperatures associated with this transition are denoted in Table 1 with $R_{s}$ and $R_{f}$ (R-phase start and finish temperatures, respectively). When comparing the transformation temperatures of the two materials, $M_{s}$ and $M_{f}$ have increased by $30^{\circ} \mathrm{C}$ in the solutionized sample. Additionally, the martensite to austenite transformation temperature range of the solutionized material is broadened, with $A_{f}$ increasing roughly by $12^{\circ} \mathrm{C}$.

Table 1: Material transformation temperatures as measured by a two-tangent method from the DSC data for the tested NiTi samples. Temperatures are the average of three heating/cooling cycles shown within one standard deviation.

\begin{tabular}{|c|c|c|c|c|c|c|}
\hline & $\mathrm{M}_{\mathrm{s}}$ & $\mathrm{M}_{\mathrm{f}}$ & $\mathrm{R}_{\mathrm{s}}$ & $\mathrm{R}_{\mathrm{f}}$ & $\mathrm{A}_{\mathrm{s}}$ & $\mathrm{A}_{\mathrm{f}}$ \\
\hline As-Received & $33 \pm 1.0^{\circ} \mathrm{C}$ & $-3 \pm 2.6^{\circ} \mathrm{C}$ & $56 \pm 0.4^{\circ} \mathrm{C}$ & $44 \pm 0.3^{\circ} \mathrm{C}$ & $57 \pm 2.4^{\circ} \mathrm{C}$ & $77 \pm 1.2^{\circ} \mathrm{C}$ \\
\hline Solutionized & $56 \pm 1.5^{\circ} \mathrm{C}$ & $34 \pm 1.6^{\circ} \mathrm{C}$ & - & - & $65 \pm 2.4^{\circ} \mathrm{C}$ & $89 \pm 1.5^{\circ} \mathrm{C}$ \\
\hline
\end{tabular}




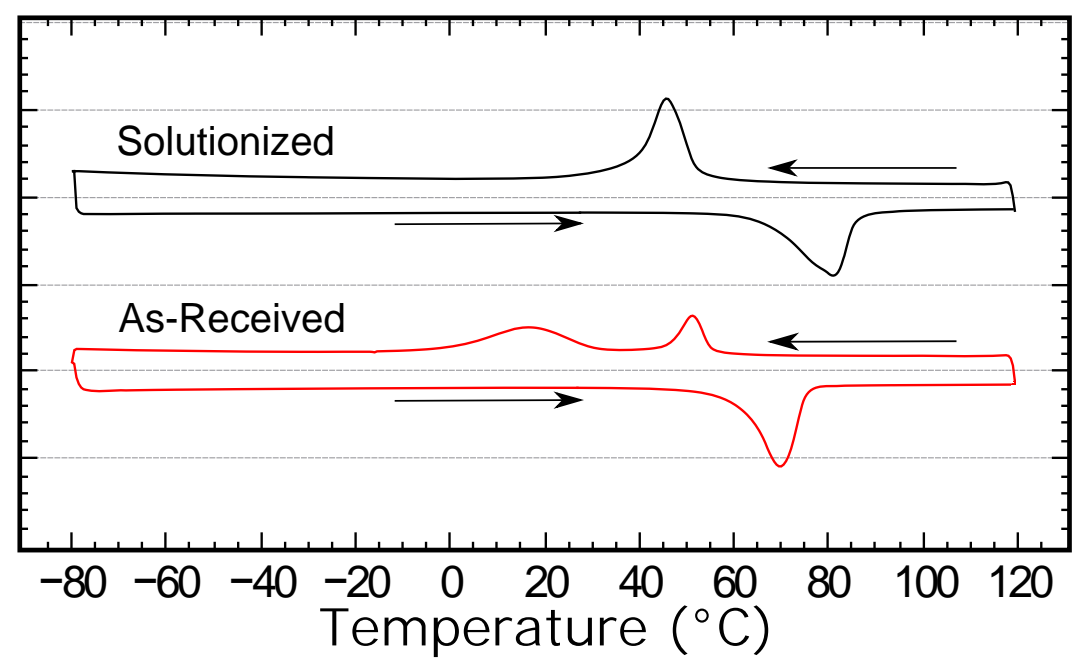

Figure 1: Characteristic DSC curves for the two tested NiTi samples: (top) as-received and (bottom) solutionized for $1000{ }^{\circ} \mathrm{C}$ for 24 hours. The as received material exhibits two cooling peaks, the first of which is characteristic of the R-phase transformation and the second is an $R$ phase to martensite transformation. The transformation temperatures are given in Table 1.

Figure 2 shows a comparison of the microstructure of as-received material as investigated by TEM (a) and solutionized sample optically imaged after chemical etching (b). The TEM reveals a very fine microstructure with a grain size of less than $100 \mathrm{~nm}$ and no visible sign of precipitate structures. By comparison, are optically resolvable at an average size of $50 \mu \mathrm{m}$ after chemical etching of the solutionized material.

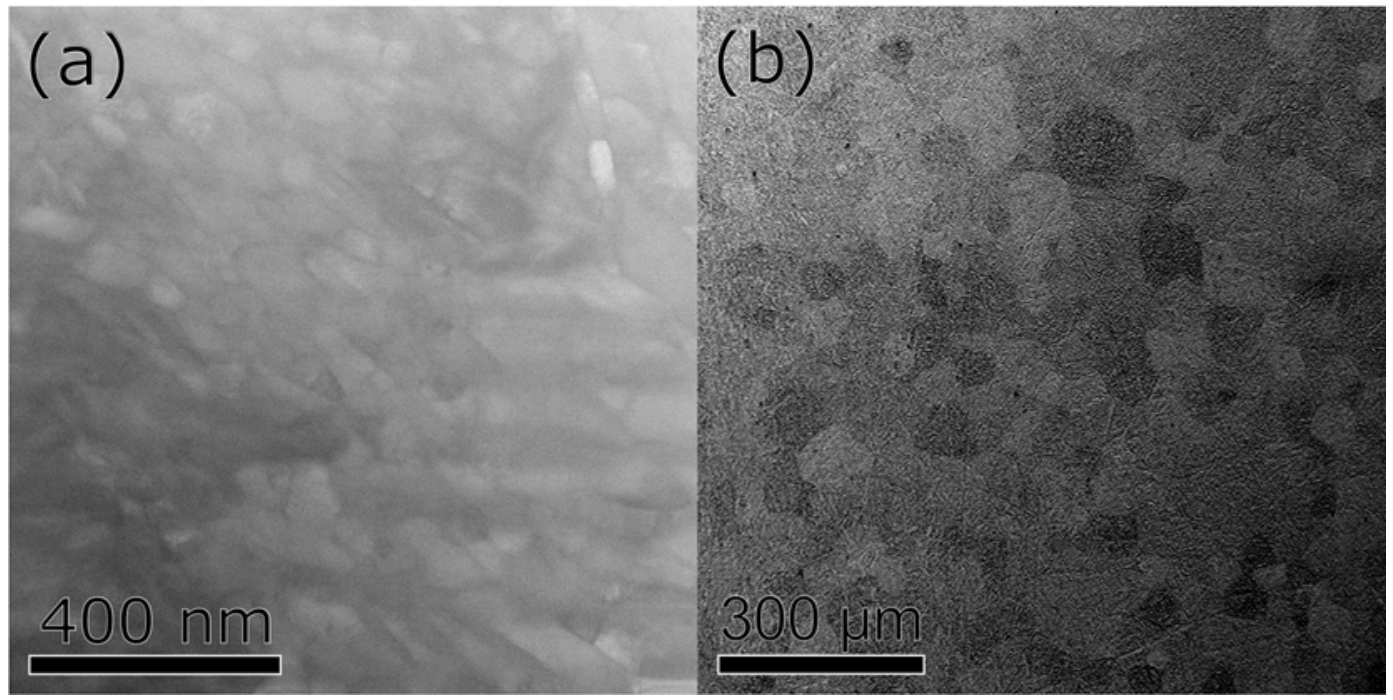

Figure 2: (a) STEM image of as-received NiTi showing a very fine microstructure with grain sizes under $100 \mathrm{~nm}$ and (b) optical microscopy image of solutionized NiTi after Kroll's etch showing much larger grain sizes of about $50 \mu \mathrm{m}$. 


\section{Shape Memory Recovery:}

Vickers microindentation of the samples was performed to test the recovery ratios consistent with previous studies (Qin et al. 2014; Frensemeier et al. 2015; Su et al. 2007). The recovery ratios were determined for the OWSME using Equation 1 through comparisons of indentation depth measurements taken initially after indentation and after in situ heating above $A_{f}$.

$R R_{\text {OW }}=\frac{d_{i}-d_{h}}{d_{i}}$

where $d_{i}$ is the depth of the initial indent and $d_{h}$ is the depth of the indent after the sample has been heated above $A_{f}$. The TWSME recovery ratio is given by Equation $\mathbf{2}$ and is calculated by comparing the depth measured after cooling below $M_{f}$ to the depth of the sample when heated above $A_{f}$.

$R R_{T W}=\frac{d_{c}-d_{h}}{d_{c}}$

where $d_{c}$ is the depth of the indent once the sample has cooled back below $M_{f}$ and $d_{h}$ is the depth of the indent when heated above $A_{f}$ ( $\mathrm{Su}$ et al. 2007). A visual representation of the measurements is shown in Figure 3, displaying a 3D profile of a Vickers indent (a) along with a corresponding cross-sectional profile of the measurements taken in the three states of interest (b). Average indentation depths at the various indentation temperatures ranged from $25.9 \mu \mathrm{m}$ to $30.3 \mu \mathrm{m}$.

(a)

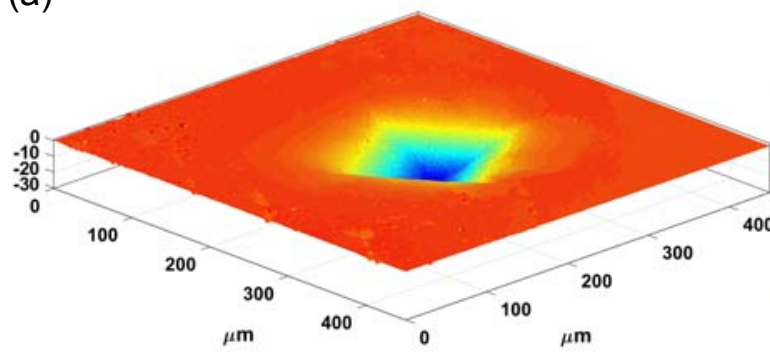

(b)

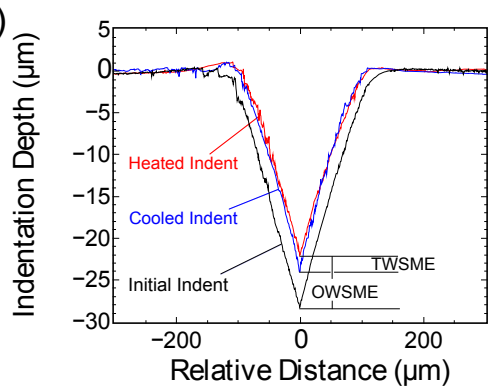

Figure 3: (a) Three dimensional laser-scanning microscope image of indent depth with all units in $\mu \mathrm{m}$, (b) plot of indent showing the three measurement states used to characterize OWSME and TWSME.

Figure 4 quantifies the recovery ratios of both the OWSME (a) and TWSME (b) as a function of the indentation temperature. Examining the overall trend in Figure 4(a) it is observed that the OWSME recovery ratios start to decrease with increasing indentation temperatures. This decrease becomes more pronounced at indentation temperatures exceeding $A_{f}$. The OWSME recovery drops from nearly $25 \%$, when indented in the martensite phase, to just under $5 \%$ when indented $31^{\circ} \mathrm{C}$ above $A_{f}$. At temperatures below $A_{s}$, the recovery appears to stagnate at about 
(a)

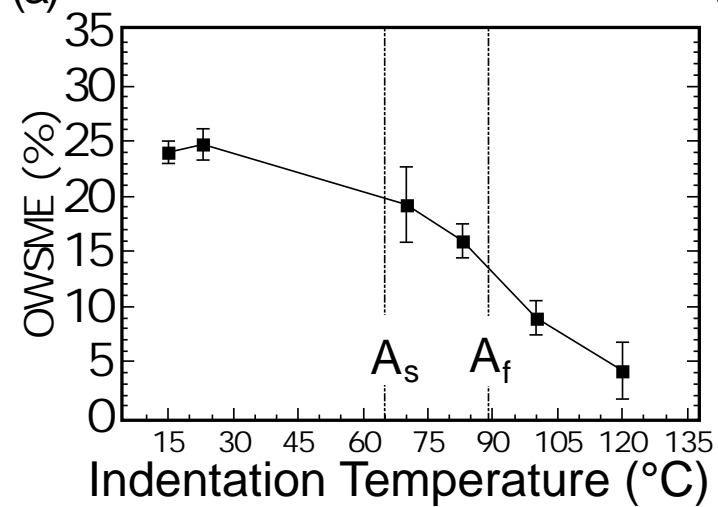

$25 \%$ recovery with decreasing indentation temperatures.

(b)

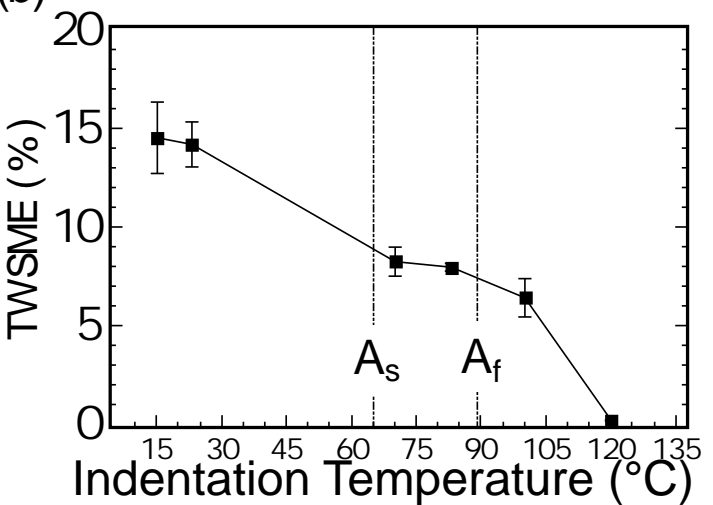

Figure 4: Recovery ratios as a function of temperature Vickers indentation for the Solutionized Material. Both the (a) OWSME and (b) TWSME recoveries. Data represents averages within one standard deviation.

Figure 4(b) shows the TWSME as a function of indentation temperature. In general, when comparing the OWSME and the TWSME similar trends are observed although the recovery magnitudes are significantly lower. When indented below $A_{s}$, the maximum recovery for the TWSME appears to stagnate at about $15 \%$; just above $A_{s}$ this recovery drops to $8 \%$. Nearing $10^{\circ} \mathrm{C}$ above $A_{f}$, where the material is expected to be fully austenitic, the TWSME can still be elicited with about $6 \%$ recovery. At indentation temperatures well above $A f$, no TWSME is measured. This is the case when the material is indented $31^{\circ} \mathrm{C}$ above $A_{f}$ with no quantifiable recovery.

\section{Polish Depth Investigation:}

Planarizing the initial idents through grinding and polishing methods and measuring the subsequent height of the protrusions upon heating as a function of polish depth yielded significant insight to the amount of affected volume below the indent which can influence the TWSME. An example of these protrusions along with profile measurements at select cycles can be seen in Figure 5. This process was repeated until no measurable protrusions remained, which characterizes the depth and volume of the region under the indent which influenced the TWSME. 

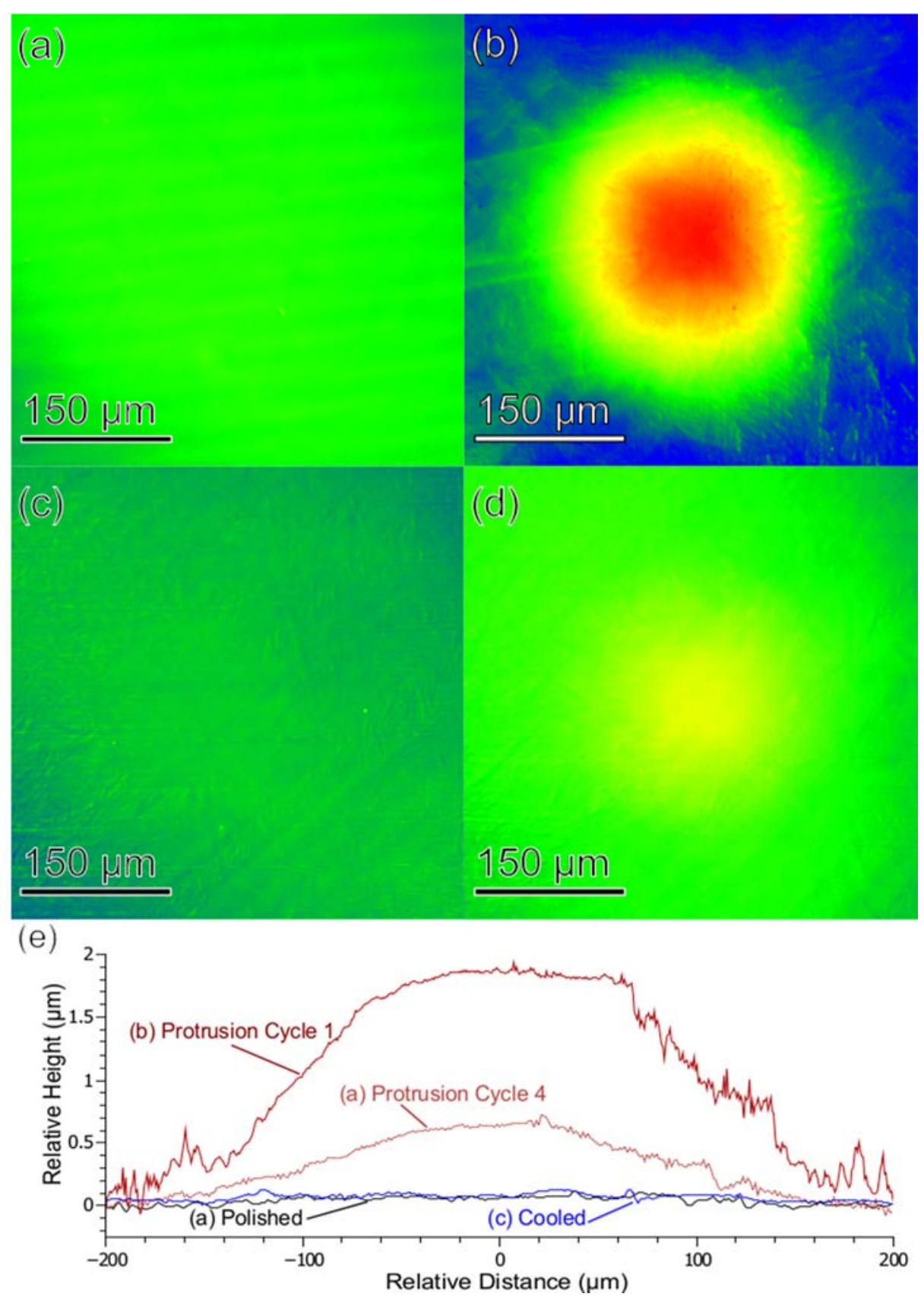

Figure 5: Laser scanning height profiles of the polished surface after removing the initial indent at room temperature (a), protrusion after heating to $90^{\circ} \mathrm{C}(\mathrm{b})$, after cooling the sample to room temperature (c), and the protrusion height after heating to $90^{\circ} \mathrm{C}$ after polishing additional 16.1 $\mu \mathrm{m}$ in depth (d). The line profiles of the protrusion heights and the flat surfaces are given in (e).

To understand the effects of various indentation temperatures on this volume, solutionized samples were indented at five varying temperatures, ranging from $15^{\circ} \mathrm{C}$ to $120^{\circ} \mathrm{C}\left(19^{\circ} \mathrm{C}\right.$ below $M_{f}$ to $31^{\circ} \mathrm{C}$ above $A_{f}$ ). For proper comparison, the results are normalized to the indentation depth of a room temperature indent. The reduction of the protrusion height as a function of polish depth can be seen in Figure 6, where both the protrusion height and the polish depth are normalized by the initial indentation depth; e.g. a polish depth of $0 \%$ corresponds to the tip of the indent prior to 
planarizing. In both the $15^{\circ} \mathrm{C}$ and the room temperature indentation, repeatable protrusions could be seen with as much as $100 \%$ of the depth of the initial indent. Similar to the recovery ratios, as indentation temperature increases above $A_{s}$ the magnitude of the protrusion height decreases. Indentations performed at higher temperatures require far less volume polished away before protrusions are no longer quantifiable. Additionally, the sample indented at $120^{\circ} \mathrm{C}$ initially produced no measurable protrusions after planarizing.

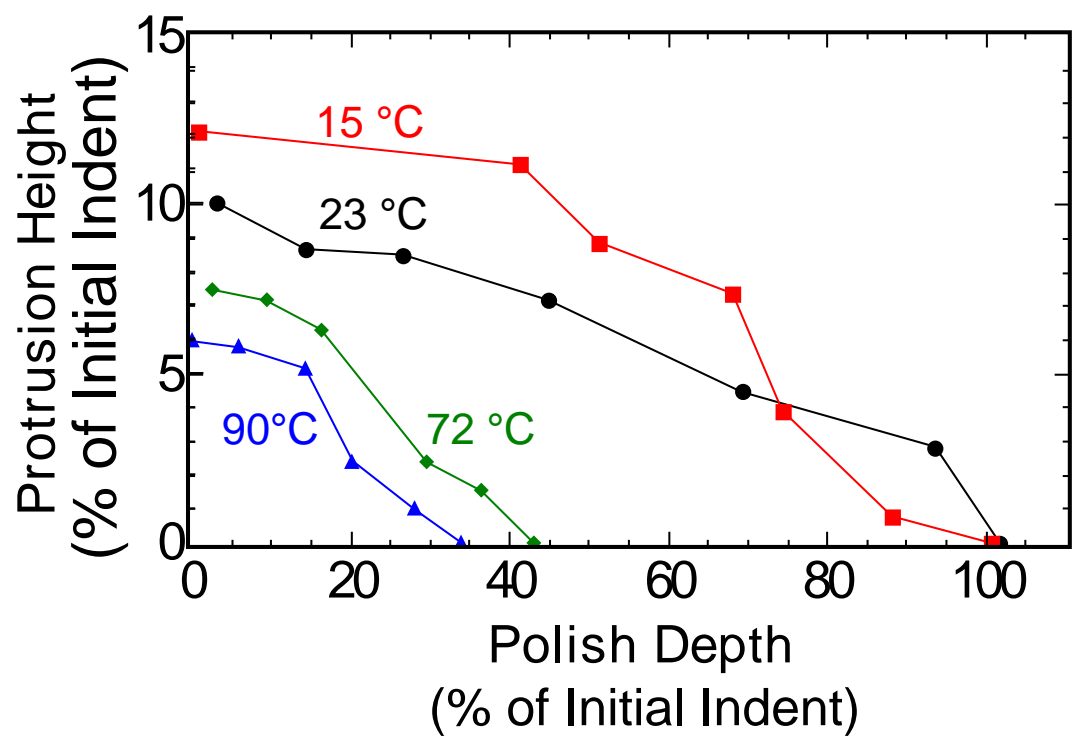

Figure 6: Reoccurring protrusion height as a function of further polishing depth along with binomial trend lines for TWSME training at $15{ }^{\circ} \mathrm{C}, 23^{\circ} \mathrm{C}$ (room temperature), $72{ }^{\circ} \mathrm{C}$, and $90^{\circ} \mathrm{C}$. A polish depth of 0 corresponds to the tip of the original indent. The polish depth and protrusion height are normalized by the depth of the initial indent.

\section{Microstructural Analysis:}

Figure 7 examines the microstructural features of a nanoindented solutionized sample as well as the bulk material through the use of TEM and SEM. A TEM lamella of the solutionized material directly under a nanoindent was imaged along with an additional TEM lamella of an area roughly $5 \mu \mathrm{m}$ away from the same indent was also fabricated and analyzed as a reference. TEM images were taken directly below an indented sample $(\mathrm{a}-\mathrm{c})$ and displaced $5 \mu \mathrm{m}$ from the indent (d). Directly underneath the indent, shown in Figure 7(a), the grain structure is very fine when compared to an area much farther underneath, Figure 7(d). A volume imageed a few hundred nanometers directly underneath the indent (Figure 7(b)) exhibits a relatively fine grain structure with a large strain contrast and evidence of dislocations. This is very similar to Figure 2(a), where grain size is less than $100 \mathrm{~nm}$ and there is high dislocation density. Diffraction patterns of this area (SAED) demonstrate a crystal structure with evidence of martensitic twinning as well as an additional ring pattern, indicating a complex crystallographic structure. Several microns apart from the indented region, the martensitic plates are much larger with clear internal twinning. The overall strain contrast is much lower, indicating a smaller dislocation density. SEM imaging in Figure 7(e) after ion milling of the area underneath the indent reveals evidence of martensitic twinning. 


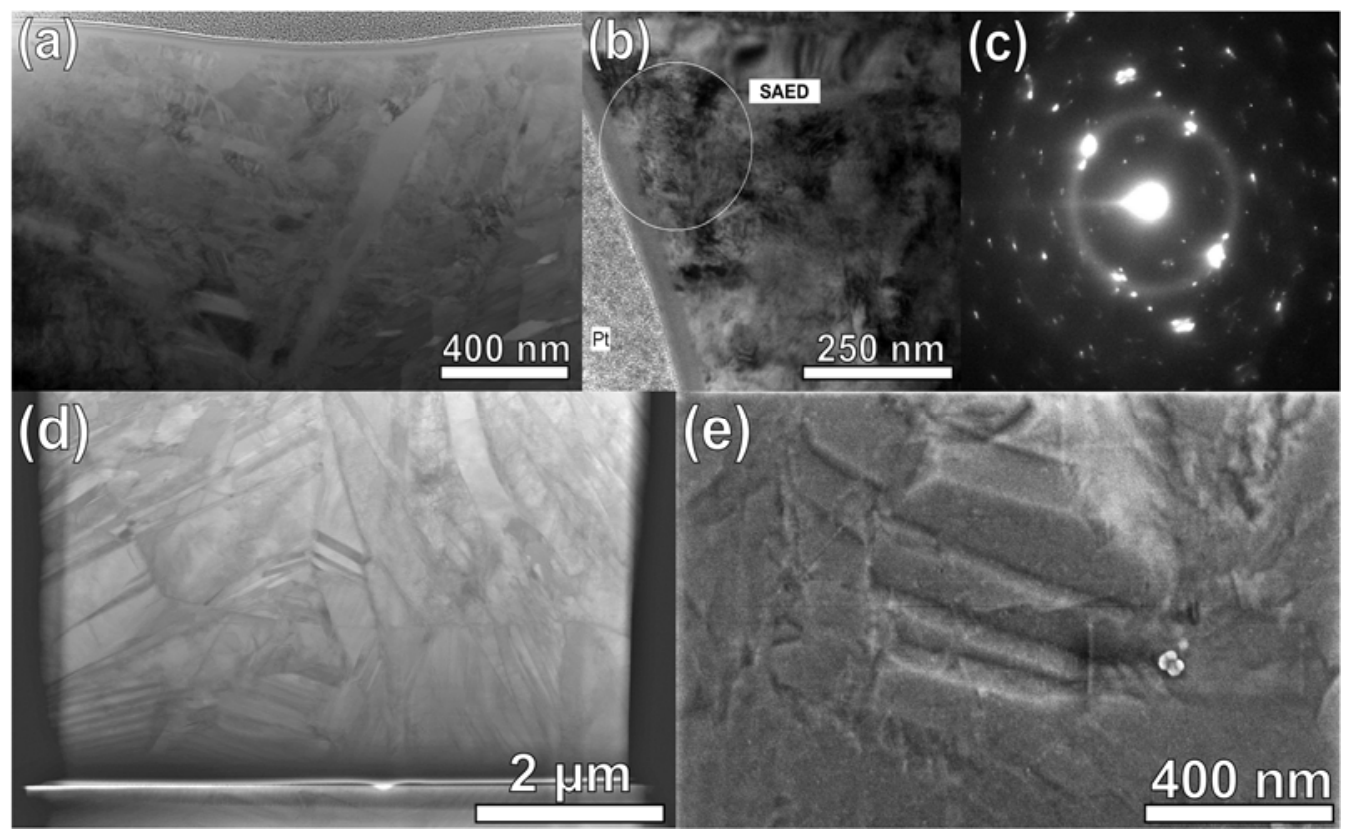

Figure 7: (a) STEM image of the area underneath the indent, showing a very fine microstructure with a high strain contrast and evidence of dislocations shown in higher magnification with (b) a TEM bright-field image with (c) the SAED pattern showing a complex crystallographic structure. Comparatively, (d) shows an STEM image far away from the indent with a larger microstructure. (g) SEM image after ion milling showing martensitic twinning underneath the indent just below the surface.

\section{Discussion:}

DSC Analysis:

The phase transition temperatures determined here for the solutionized material are similar to those observed in previous studies with similar composition (Fei et al. 2012; Ye \& Cheng 2012). In contrast, the as-received material exhibits a two-step phase transition in the as-received material which is not commonly observed in this NiTi composition. This transition is commonly associated with the R-phase, i.e. an intermediate rhombohedral crystal structure preceding the B19' martensitic transformation from the B2 austenite (Zhang \& Sehitoglu 2004; Otsuka \& Ren 1999; Otsuka \& Ren 2005; Goo \& Sinclair 1985). Generally, the R-phase is seen in compositions with slightly higher nickel content, typically above Ti-50.5at\%Ni (Khalil Allafi et al. 2002; Khalil-Allafi et al. 2002), and can be induced with proper heat treatment and the formation of precipitate structures (Cong et al. 2014; Wang, Verlinden, et al. 2015; Wang, Kustov, et al. 2015). Studies on NiTi compositions of lower nickel content suggest that the R-phase transformation can be induced through a combination of heat treatment and material processing, such as cold working (Mahmud et al. 2008; Okamoto et al. 1988; Todoroki 1985; Todoroki \& Tamura 1986; Favier \& Liu 2000; Goo \& Sinclair 1985). It has also been proposed that grain sizes below $150 \mathrm{~nm}$ in Ni-rich NiTi can impede the formation of precipitate structures in NiTi (Prokofiev et al. 2010). Figure 2(a) shows 
that the as-received microstructure is very fine and precipitate structures are not observed. The effects of the solutionizing process are further confirmed by the larger crystal sizes seen in the heat treated material shown in Figure 2 (b). All things considered, it is likely that the R-phase in the as-received material is a consequence of the material's deformation during manufacturing. In the solutionized state, both the increased transformation temperatures and the removal of the R-Phase can be attributed to the removal of some of the deformation substructure via the heat treatment process. Cold working has been shown to influence the transition temperatures of NiTi lowering the transformation temperatures (Gibkes et al. 2004; Daly et al. 2012; Lin et al. 1991). Ultimately, the relatively large grain size and more importantly the low dislocation density of the solutionized microstructure is much less complicated than the as-received, and therefore a better choice of this study. Therefore, experimentation only focused on solutionized samples.

\section{Shape Memory Recovery:}

Several studies have previously observed the indentation-induced OWSME through the use of sharp indenters. A bulk of these studies have focused on alloys with slightly higher $\mathrm{Ni}$ content (Frensemeier et al. 2015; Qin et al. 2014; Troyon \& Huang 2005; Frick et al. 2005; Ni et al. 2003), NiTi thin films (Shaw et al. 2003; Shaw et al. 2005), and CuAlNi shape memory alloys (Liu et al. 2005; Crone et al. 2007). The OWSME at room temperature exhibits a $24 \%$ recovery (Figure 4(a)), which is as expected when compared to previously reported values for Vickers indentation which range from $23 \%$ to $30 \%$ (Frick et al. 2005; Shaw et al. 2003; Frick et al. 2006). As the stress state generated by Vickers indentation is self-similar, direct comparisons between these studies can be made, regardless of indentation depth. Thereby, the observations in Figure 4(a) are expected to hold for NiTi of other compositions.

Typically, deformation of NiTi above $A_{f}$ leads to pseudoelasticity. However, many studies have shown shape recovery is possible above $A_{f}$ through indentation (Ni et al. 2003; Qin et al. 2014; Frensemeier et al. 2015; Su et al. 2007). This observation has been explicitly studied by Zhan et al., where they conclude the hydrostatic component of the stress state during indentation effectively increases the transformation temperatures (Zhang et al. 2005). Consequently, the stressinduced martensite remains stable above $A_{f}$. Their results demonstrated that the stress necessary to induce this transformation is reduced nearly $150 \%$ when hydrostatic stress is accounted for. Consequently, shape recovery observed at temperatures above $A_{f}$ (Figure 4(a)) are consistent with previous work, and expected.

Similar to the OWSME, the TWSME can also be elicited in materials at indentation temperatures above $A_{f}$. In addition to the results shown here, the TWSME has been studied through Vickers indentation in Ti-50.9at\%Ni alloy (Qin et al. 2014) and in a Ti-50.6at\%Ni alloy (Su et al. 2007) at temperatures above $A_{f}$. The results of both of these studies show that the indentationinduced TWSME can produce recovery ratios of about $7 \%$ just above $A_{f}$ which is comparable to the $6.4 \%$ recovery observed in Figure 4(b). The significant amount of two-way recovery seen in the present and both of the aforementioned studies just above $A_{f}$ is a reflection of the stabilized martensite beneath the indent.

Spherical indentation simulations in austenitic NiTi to determine the effective plastic strains have been conducted by finite element modeling (Zhang, Cheng \& Grummom 2007; Zhang, Cheng \& Grummon 2007; Maletta et al. 2012). Maletta et al. categorizes the volume under the indented specimen into four regions emanating from the indent: thermally stabilized martensite directly under the indent, transformed martensite, a transformation region where some combination of austenite and martensite exist, and finally untransformed austenite (Maletta et al. 
2012). Despite the simulations modeling a spherical indenter, it can be expected that the stress state generated by Vickers indentation produces a similar four region volume underneath the indent. As the stress needed to generate martensite is higher at elevated temperatures, it can be expected that these regions decrease in relative volume with increasing temperature. This is consistent with the results in Figure 6, where the effective volume of material which influences the TWSME protrusions decreases with increasing temperature.

A recent publication by Frensemeier et al. uncovered that the indentation-induced TWSME in a Ni-rich alloy (Ti-50.9at\% $\mathrm{Ni}$ ) is diminished if thermal cycling is performed to a temperature much higher than $A_{f}$ (Frensemeier et al. 2015). Similar observations have been made throughout the course of the present study. Furthermore, the results of Frensemeier et al. display a 9.0\% recovery when indented just below $A_{s}$ which is comparable to the $8.4 \%$ observed here. However, when the Ni-rich alloy was either solutionized or aged at $550^{\circ} \mathrm{C}$ and indented at room temperature (about $26^{\circ} \mathrm{C}$ and $19^{\circ} \mathrm{C}$ above $A f$, respectively), no TWSME was observed. Similarly, no TWSME is seen when indented at $31^{\circ} \mathrm{C}$ above $A_{f}$ in the present study. The lack of TWSME in samples indented at much higher temperatures can be attributed to absence of thermally stable martensite when heated above $A_{f}$. Indentation temperatures above $A_{f}$ will impede the stabilization of martensite and thus lower the TWSME recovery.

\section{Polish Depth Investigation:}

Measuring the stable cyclic protrusion height as a function of polish depth can provide an understanding of the relative volume of material which influences the TWSME. When samples are indented below $A_{s}$ the stable protrusions can be seen even when approaching polish depths nearing $100 \%$ of the initial indent. The volume that influences the TWSME below the indent is considerably deep, especially when compared to indents made at temperatures above $A f$.

In a similar study by Fei et al., the stable cyclic protrusion height of a TWSME switchable surface produced by spherical and cylindrical indentation was investigated by systematically removing material underneath the indent through a polishing method. Their results displayed that as the polishing depth increases and more material is removed, the stable protrusion height decreases in a linear relationship for the cylindrical indents and a quadratic relationship for the spherical indents (Fei et al. 2009). The trend seen in Figure 6 appears more linear. This linearity is likely a consequence of the self-similar stress state created by Vickers indentation.

Not only are the magnitudes of the TWSME considerably lower when samples are indented at elevated temperatures $\left(72^{\circ} \mathrm{C}\right.$ and $\left.90^{\circ} \mathrm{C}\right)$, but also the amount of polishing necessary to remove any trace of the TWSME is less than half of what is measured in the samples that were indented below $A_{s}$. It is clear that the effective volume which contributes to the TWSME protrusions decreases with increasing indentation temperature. This is consistent with the TWSME recovery ratio observations in which TWSME recovery decreases with increasing indentation temperature. It is possible that this "effective volume" can be correlated to the amount of stabilized martensite in the sample. When indented at $120^{\circ} \mathrm{C}$ this volume not quantifiable, validating that the TWSME can no longer be elicited through the indentation techniques at some critical temperature. This is likely a consequence of the relative absence of stabilized martensite generated through indentation at this temperature and above.

Microstructural Analysis: 
TEM results of the solutionized sample reveal that the microstructure underneath the indents differs significantly from that of the initial material. The discrepancy between these two locations is due to the deformation created by the causing a high dislocation density directly underneath the indent. Comparing the deformed microstructure directly under the indent of the solutionized material to that of the bulk solutionized material, it can be seen that, after indentation, the grain size decreases greatly. It has also been previously noted that the martensitic transformation, through either thermal cycling or pseudoelasticity, can exacerbate the dislocation density seen in the material (Eggeler et al. 2004; Raj \& Noebe 2013; Bowers et al. 2015; Norfleet et al. 2009; Simon et al. 2010). As the apparent cold working in the as-received state played a role in manipulating the transition temperatures, it is also likely that indentation can have similar effects. The deformation associated with indentation could potentially cause a local change in the transition temperatures assisting in the formation of locally stabilized martensite in the area of the indent.

\section{Conclusion:}

The effect of indentation temperature on the indentation induced shape memory effect in a solutionized Ti-50.3at\% Ni was studied. In general, as indentation temperatures increased the magnitude of the shape memory recoveries decreased linearly; this is a reflection of the ClausiusClapreyon relation and the stress gradient beneath the indent, which in combination limit the volume of deformed material with increasing temperature. Planarizing the material after indentation followed by thermal cycling resulted in switchable surface protrusions. The protrusion height was measured as a function of polish depth, and nearly $100 \%$ of the initial indentation depth must be removed below the indent for the TWSME to be completely removed. Protrusion height decreased linearly with polish depth with the linearity likely being a consequence of the selfsimilar stress state generated by Vickers indentation. With increased indentation temperature the volume influencing the TWSME decreases significantly, and approximately $30^{\circ} \mathrm{C}$ above $A_{f}$ this volume is nonexistent. TEM directly beneath the indent in the solutionized material revealed a microstructure, being much finer than the bulk solutionized material. The finer microstructure below the indent may play a role in locally increasing the transformation temperatures influencing the stabilization of martensite. Overall these results show that indentation below $M_{f}$ result in larger OWSME and TWSME deformation recovery. 


\section{Acknowledgements:}

CPF gratefully acknowledges support from the National Science Foundation (NSF) CAREER award (Grant No. DMR-1255603), as well as the University of Wyoming International Travel Grant. Eduard Arzt, INM and Saarland University, is acknowledged for a critical reading of the manuscript.

\section{References:}

Adler, P.H. et al., 1990. On the Tensile and Torsional Properties of Pseudoelastic NiTi. Scripta Metallurgica, 24, pp.943- 947.

Benafan, O. et al., 2012. Role of B19' martensite deformation in stabilizing two-way shape memory behavior in NiTi. Journal of Applied Physics, 112(9), pp.1-12.

Bowers, M.L. et al., 2015. ScienceDirect Austenite grain refinement during load-biased thermal cycling. Acta Materialia, 91, pp.318-329. Available at: http://dx.doi.org/10.1016/j.actamat.2015.03.017.

Buehler, W.J., Gilfrich, J. V. \& Wiley, R.C., 1963. Effect of Low-Temperature Phase Changes on the Mechanical Properties of Alloys near Composition TiNi. Journal of Applied Physics, 34(5), pp.1475-1477.

Cong, D.Y., Saha, G. \& Barnett, M.R., 2014. Thermomechanical properties of Ni-Ti shape memory wires containing nanoscale precipitates induced by stress-assisted ageing. Acta biomaterialia, 10(12), pp.5178-92. Available at: http://www.ncbi.nlm.nih.gov/pubmed/25159371.

Crone, W.C., Brock, H. \& Creuziger, A., 2007. Nanoindentation and microindentation of cuAlNi shape memory alloy. Experimental Mechanics, 47(1), pp.133-142.

Daly, M. et al., 2012. Fabrication of a novel laser-processed NiTi shape memory microgripper with enhanced thermomechanical functionality. Journal of Intelligent Material Systems and Structures, 24(8), pp.984-990. Available at: http://jim.sagepub.com/cgi/doi/10.1177/1045389X12444492.

Eggeler, G. et al., 2004. Structural and functional fatigue of NiTi shape memory alloys. Materials Science and Engineering A, 378(1-2 SPEC. ISS.), pp.24-33.

Erbstoeszer, B. et al., 2000. Stabilization of the shape memory effect in NiTi: an experimental investigation. Scripta Materialia, 42(12), pp.1145-1150.

Faiella, G. \& Antonucci, V., 2015. Experimental Characterization of Shape Memory Alloys. In Shape Memory Alloy Engineering. Elsevier Ltd, pp. 57-77. Available at: http://dx.doi.org/10.1016/B978-0-08-099920-3.00003-6.

Favier, D. \& Liu, Y., 2000. Restoration by rapid overheating of thermally stabilised martensite of NiTi shape memory alloys. Journal of Alloys and Compounds, 297(1-2), pp.114-121.

Fei, X. et al., 2012. Surface form memory in NiTi shape memory alloys by laser shock indentation. Journal of Materials Science, 47(5), pp.2088-2094.

Fei, X., Zhang, Y. \& Grummon, D.S., 2009. Indentation-induced two-way shape memory surfaces. Journal of Materials Research, 24(03), pp.823 - 830.

Frensemeier, M. et al., 2015. Indentation-induced two-way shape-memory effect in aged Ti-50.9 at.\% Ni. MRS Communications, 5(01), pp.77-82. Available at: http://www.journals.cambridge.org/abstract_S2159685914000378. 
Frick, C.P. et al., 2006. Stress-induced martensitic transformations and shape memory at nanometer scales. Acta Materialia, 54(8), pp.2223-2234.

Frick, C.P. et al., 2005. Thermal processing of polycrystalline NiTi shape memory alloys. Materials Science and Engineering A, 405(1-2), pp.34-49.

Fukuda, T. et al., 1997. Two-Way Shape Memory Properties of a Ni-Rich Ti-Ni Alloy Aged under Tensile-Stress. Materials Transactions, JIM, 38(6), pp.514-520.

Fukuda, T. et al., 2001. Two-Way Shape Memory Properties of a Ti-51Ni Single Crystal Including Ti3Ni4 Precipitates of a Single Variant. Materials Transactions, 42(2), pp.323 - 328. Available at: http://www.jim.or.jp/journal/e/pdf3/42/02/323.pdf.

Gibkes, J. et al., 2004. Local influence of material processing on phase transitions in NiTi shape memory alloys investigated by IR thermography. Materials Science and Engineering A, 378(1-2), pp.175-179. Available at: papers2://publication/uuid/4B120B60-16E7-47E99AF6-14F0551C9ADF.

Goo, E. \& Sinclair, R., 1985. The B2 To R Transformation in Ti50Ni47Fe3 and Ti49.5Ni50.5 alloys. Acta Metallurgica, 33(9), pp.1717-1723.

Huang, W.M. et al., 2005. Pile-up and sink-in in micro-indentation of a NiTi shape-memory alloy. Scripta Materialia, 53(9), pp.1055-1057. Available at: http://linkinghub.elsevier.com/retrieve/pii/S1359646205004057.

Khalil Allafi, J., Ren, X. \& Eggeler, G., 2002. The mechanism of multistage martensitic transformations in aged Ni-rich NiTi shape memory alloys. Acta Materialia, 50(4), pp.793803.

Khalil-Allafi, J., Dlouhy, A. \& Eggeler, G., 2002. Ni4Ti3-precipitation during aging of NiTi shape memory alloys and its influence on martensitic phase transformations. Acta Materialia, 50(17), pp.4255-4274. Available at: <Go to ISI>://WOS:000178609500005.

Lahoz, R., Gracia-Villa, L. \& Puértolas, J.A., 2002. Training of the Two-Way Shape Memory Effect by Bending in NiTi Alloys. Journal of Engineering Materials and Technology, 124(4), p.397. Available at: http://materialstechnology.asmedigitalcollection.asme.org/article.aspx?articleid=1426814.

Lahoz, R. \& Puértolas, J.A., 2004. Training and two-way shape memory in NiTi alloys: Influence on thermal parameters. Journal of Alloys and Compounds, 381(1-2), pp.130-136.

Laplanche, G., Pfetzing-Micklich, J. \& Eggeler, G., 2014a. Orientation dependence of stressinduced martensite formation during nanoindentation in NiTi shape memory alloys. Acta Materialia, 68, pp.19-31. Available at: http://linkinghub.elsevier.com/retrieve/pii/S1359645414000159.

Laplanche, G., Pfetzing-Micklich, J. \& Eggeler, G., 2014b. Sudden stress-induced transformation events during nanoindentation of NiTi shape memory alloys. Acta Materialia, 78, pp.144160. Available at: http://linkinghub.elsevier.com/retrieve/pii/S1359645414004170.

Larsson, P.L. et al., 1996. Analysis of Berkovich indentation. International Journal of Solids and Structures, 33(2), pp.221-248.

Li, C.-H. et al., 2008. Cold Rolling-Induced Multistage Transformation in Ni-Rich NiTi Shape Memory Alloys. Materials Transactions, 49(9), pp.2136-2140. Available at: 
http://joi.jlc.jst.go.jp/JST.JSTAGE/matertrans/MER2008138?from=CrossRef.

Lin, H.C. et al., 1991. The effects of cold rolling on the martensitic transformation of an equiatomic TiNi alloy. Acta Metallurgica et Materialia, 39(9), pp.2069-2080.

Lin, H.C. \& Wu, S.K., 1993. Determination of heat of transformation in a cold-rolled martensitic tini alloy. Metallurgical Transactions A, 24(2), pp.293-299.

Ling, H.C. \& Kaplow, R., 1980. Phase transitions and shape memory in NiTi. Metallurgical and Materials Transactions A, 11(1), pp.77-83.

Liu, C., Zhao, Y.P. \& Yu, T., 2005. Measurement of microscopic deformation in a CuAlNi single crystal alloy by nanoindentation with a heating stage. Materials and Design, 26(5), pp.465468.

Liu, Y. et al., 2006. Effect of incomplete thermal cycling on the transformation behaviour of NiTi. Materials Science and Engineering A, 435-436, pp.251-257.

Liu, Y. et al., 2008. Partial thermal cycling of NiTi. Journal of Alloys and Compounds, 449(1-2), pp.144-147.

Liu, Y. \& Favier, D., 2000. Stabilisation of martensite due to shear deformation via variant reorientation in polycrystalline NiTi. Acta Materialia, 48(13), pp.3489-3499.

Liu, Y., Liu, Y. \& Van Humbeeck, J., 1998. Two-way shape memory effect developed by martensite deformation in NiTi. Acta Materialia, 47(1), pp.199-209.

Liu, Y. \& McCormick, P.G., 1990. Factors influencing the development of two-way shape memory in NiTi. Acta Metallurgica et Materialia, 38(7), pp.1321-1326.

Mahmud, A.S. et al., 2008. Effect of annealing on deformation-induced martensite stabilisation of NiTi. Intermetallics, 16(2), pp.209-214.

Maletta, C. et al., 2012. Indentation response of a NiTi shape memory alloy: modeling and experiments. , 21, pp.5-12.

Miyazaki, S. et al., 1982. CHARACTERISTICS OF DEFORMATION AND TRANSFORMATION PSEUDOELASTICITY IN Ti-Ni ALLOYS. Le Journal de Physique Colloques, 43(C4), pp.255 - 260.

Miyazaki, S. \& Otsuka, K., 1986. Deformation and Transition Behavior Associated with the RPhase in Ti-Ni Alloys. Metallurgical Transaction A, 17(January), pp.53-63.

Nagasawa, A. et al., 1974. Reversible Shape Memory Effect. Scripta Metallurgica, 8, pp.10551060.

Ng, K.L. \& Sun, Q.P., 2006. Stress-induced phase transformation and detwinning in NiTi polycrystalline shape memory alloy tubes. Mechanics of Materials, 38(1-2), pp.41-56. Available at: http://linkinghub.elsevier.com/retrieve/pii/S0167663605000852.

Ni, W., Cheng, Y.T. \& Grummon, D.S., 2003. Microscopic superelastic behavior of a nickeltitanium alloy under complex loading conditions. Applied Physics Letters, 82(17), pp.28112813.

Ni, W., Cheng, Y.-T. \& Grummon, D.S., 2002. Recovery of microindents in a nickel-titanium shape-memory alloy: A "self-healing" effect. Applied Physics Letters, 80(18), pp.3310-3312.

Nishida, M. \& Honma, T., 1984. All-Round Shape Memory Effect in Ni-Rich TiNi Alloys 
Generated by Constrained Aging. Scripta Metallurgicai, 18, pp.1293-1298.

Norfleet, D.M. et al., 2009. Transformation-induced plasticity during pseudoelastic deformation in $\mathrm{Ni}$ - Ti microcrystals. Acta Materialia, 57(12), pp.3549-3561. Available at: http://dx.doi.org/10.1016/j.actamat.2009.04.009.

Okamoto, Y. et al., 1988. Reversible changes in yield stress and transformation temperature of a NiTi alloy by alternate heat treatments. Scripta Metallurgica, 22(4), pp.517-520. Available at: http://www.sciencedirect.com/science/article/pii/0036974888900166.

Otsuka, K. \& Ren, X., 2005. Physical metallurgy of Ti-Ni-based shape memory alloys. Progress in Materials Science, 50(5), pp.511-678.

Otsuka, K. \& Ren, X.B., 1999. Recent developments in the research of shape memory alloys. Intermetallics, 7(5), pp.511-528. Available at: <Go to ISI>://WOS:000079644900001.

Otsuka, K. \& Wayman, C.M., 1998. An Introduction to Martensite and Shape Memory. In Shape Memory Materials. London: Butterworth-Heinemann, pp. 3 - 20.

Patel, J.R. \& Cohen, M., 1953. Criterion for the action of applied stress in the martensitic transformation. Acta Metallurgica, 1, pp.531-538.

Perkins, J., 1974. Residual Stresses and the Origin of Reversible (Two-Way) Shape Memory Effects. Scripta Metallurgica, 8, pp.1469-1476.

Peter, N.J. et al., 2013. Indentation-induced two-way shape-memory effect in NiTi. In NEMS. pp. $1131-1134$.

Prokofiev, E. a. et al., 2010. Suppression of Ni4Ti3 Precipitation by Grain Size Refinement in NiRich NiTi Shape Memory Alloys. Advanced Engineering Materials, 12(8), pp.747-753. Available at: http://doi.wiley.com/10.1002/adem.201000101.

Qin, E. et al., 2014. Vickers Indentation Induced One-Way and Two-Way Shape Memory Effect in Austenitic NiTi. Advanced Engineering Materials, 16(1), pp.72-79. Available at: http://doi.wiley.com/10.1002/adem.201300219.

Raj, S. V \& Noebe, R.D., 2013. Materials Science \& Engineering A Low temperature creep of hotextruded near-stoichiometric NiTi shape memory alloy part II : Effect of thermal cycling. Materials Science \& Engineering A, 581, pp.154-163. Available at: http://dx.doi.org/10.1016/j.msea.2013.04.095.

Sato, M., Ishida, A. \& Miyazaki, S., 1998. Two-way shape memory effect of sputter-deposited thin films of Ti 51.3 at\% Ni. Thin Solid Films, 315(1-2), pp.305-309. Available at: $<$ Go to ISI>://WOS:000074265800050\nhttp://ac.els-cdn.com/S0040609097007463/1-s2.0S0040609097007463main.pdf?_tid=11cc6136956e23ec0846a3e7af6592cf\&acdnat=1339723515_399e598922d2 be0bfa 7 a 87 a 9 cfdd 905 c.

Scherngell, H. \& Kneissl, A.C., 2002. Generation, development and degradation of the intrinsec two-way shape memory effect in different alloy systems. Acta materialia, 50(2), p.327. Available at: http://www.sciencedirect.com/science/article/pii/S1359645401003421.

Scherngell, H. \& Kneissl, A.C., 1999. Influence of the microstructure on the stability of the intrinsic two-way shape memory effect. Materials Science and Engineering: A, 273-275, pp.400-403. 
Sehitoglu, H. et al., 2001. Shape memory and pseudoelastic behavior of 51.5\%Ni-Ti single crystals in solutionized and overaged state. Acta Materialia, 49(17), pp.3609-3620.

Shaw, G. a. et al., 2003. Shape memory effect in nanoindentation of nickel-titanium thin films. Applied Physics Letters, 83(2), pp.257-259.

Shaw, G. a. et al., 2005. Thermomechanical high-density data storage in a metallic material via the shape-memory effect. Advanced Materials, 17(9), pp.1123-1127.

Shaw, J., 1995. Thermomechanical aspects of NiTi. Journal of the Mechanics and Physics of Solids, 43(8), pp.1243-1281.

Simon, T. et al., 2010. On the multiplication of dislocations during martensitic transformations in NiTi shape memory alloys. , 58, pp.1850-1860.

Su, J.F., Huang, W.M. \& Hong, M.H., 2007. Indentation and two-way shape memory in a NiTi polycrystalline shape-memory alloy. Smart Materials and Structures, 16(1), pp.S137-S144.

Suresh, S. \& Giannakopoulos, A.E., 1998. A new method for estimating residual stresses by instrumented sharp indentation. Acta Materialia, 46(16), pp.5755-5767.

Tang, W., 1997. Thermodynamic study of the low-temperature phase B19' and the martensitic transformation in near-equiatomic Ti-Ni shape memory alloys. Metallurgical and Materials Transactions A, 28(3), pp.537-544. Available at: http://link.springer.com/article/10.1007/s11661-997-0041-6.

Tang, W., Cederstrom, J. \& Sandstrom, R., 1991. Property Database for the Development of Shape Memory Alloy Applications. Journal de Physique IV, 1, pp.129 -134.

Tas, H., Delaey, L. \& Deruyttere, a., 1972. Stress-induced transformations and the shape-memory effect. Journal of the Less Common Metals, 28(1), pp.141-151.

Todoroki, T., 1985. Two-way Memory Behavior and Phase Transformations in Ti-Ni Alloy. $J$. Japan Inst. Metals, 49(6), pp.439 - 444.

Todoroki, T. \& Tamura, H., 1986. Deformation Behaviour of a Thermally Cycled Ti-Ni Alloy Coil under Applied Stress. J. Japan Inst. Metals, 50(6), pp.538 - 545.

Troyon, M. \& Huang, L., 2005. Correction factor for contact area in nanoindentation measurements. Journal of Materials Research, 20, pp.610-617.

Vaidyanathan, R., Bourke, M.A.M. \& Dunand, D.C., 1999. Stress-induced martensitic transformations in NiTi and NiTi-TiC composites investigated by neutron diffraction. Materials Science and Engineering: A, 273-275, pp.404-409. Available at: http://www.sciencedirect.com/science/article/pii/S092150939900307X.

Wang, X., Kustov, S., et al., 2015. Effect of nanoprecipitates on the transformation behavior and functional properties of a Ti-50.8at.\% Ni alloy with micron-sized grains. Acta Materialia, 82, pp.224-233.

Available

at: http://www.sciencedirect.com/science/article/pii/S1359645414006971.

Wang, X., Verlinden, B. \& Van Humbeeck, J., 2015. Effect of post-deformation annealing on the R-phase transformation temperatures in NiTi shape memory alloys. Intermetallics, 62, pp.4349. Available at: http://www.sciencedirect.com/science/article/pii/S0966979515000503.

Wasilewski, R.J., 1975. On the "reversible shape memory effect" in martensitic transformation. Scripta Metallurgica, 9(4), pp.417-421. 
Ye, C. \& Cheng, G.J., 2012. Scalable patterning on shape memory alloy by laser shock assisted direct imprinting. Applied Surface Science, 258(24), pp.10042-10046.

Zhang, X. \& Sehitoglu, H., 2004. Crystallography of the B2 -> R -> B19' phase transformations in NiTi. Materials Science and Engineering A, 374(1-2), pp.292-302.

Zhang, Y., Cheng, Y.-T. \& Grummom, D.S., 2007. Novel tribological systems using shape memory alloys and thin films. Surface and Coatings Technology, 202(4-7), pp.998-1002.

Zhang, Y., Cheng, Y.-T. \& Grummon, D.S., 2005. Indentation stress dependence of the temperature range of microscopic superelastic behavior of nickel-titanium thin films. Journal of Applied Physics, 98(3), p.033505.

Available

at: http://scitation.aip.org/content/aip/journal/jap/98/3/10.1063/1.1994934.

Zhang, Y., Cheng, Y.-T. \& Grummon, D.S., 2006. Two-way indent depth recovery in a NiTi shape memory alloy. Applied Physics Letters, 88(13), pp.3-6.

Zhang, Y., Cheng, Y.-T. \& Grummon, D.S., 2007. Understanding indentation-induced two-way shape memory effect. Journal of Materials Research, 22(10), pp.2851-2855. 